\title{
Educating the Commons and Commoning Education: Thinking Radical Education with Radical Technology
}

\author{
Grégoire Rousseau and Nora Sternfeld
}

\section{INTRODUCTION}

This chapter is designed as a conversation. The dialogue facilitates the encounter between our two positions within what this book calls PostDigital, Post-Internet Art and Education, allowing us to articulate our standpoints and current practices. To do this we decided deliberately to leave post-internet as the label for a certain kind of artistic approach behind. Our aim is to come further with a more concretely engaged questioning based on the wish to work on what could come after the post of post-internet-as it felt nothing but a form of being stuck to us. In contrast our approach intends to engage and question concretely what could be a common practice distant from thinking art as the value form

G. Rousseau

Helsinki, Finland

e-mail: mail@stationofcommons.org

N. Sternfeld $(\bowtie)$

Hochschule für bildende Künste Hamburg, Hamburg, Germany

e-mail: nora.sternfeld@hfbk-hamburg.de

(C) The Author(s) 2021

K. Tavin et al. (eds.), Post-Digital, Post-Internet Art and Education, Palgrave Studies in Educational Futures, https://doi.org/10.1007/978-3-030-73770-2_7 
of capitalism or aesthetic experience as a direct expression of corporate spectacle.

We know what being stuck in capitalism means; cynicism, art as branding, and in fine artistic practice as a form of entrepreneurship. We know that our survival depends to a certain extent in its affirmation, we know it and do it with every line, with every click, but we want to insist and persist with imagining other possible structures for education and for technology. In this sense we situate this dialogue in a state that aims to work through and overcome cynicism. We want to imagine another collective gesture, one that would form the objective conditions of production for this new space situated in, against, and beyond capitalism.

Considering the post-digital as a condition of our time, we begin the dialogue by together thinking through our respective experiences. This encounter inquires into, but also questions, the potential role of current radical/critical ideas/position/theory within a technological context. The intention is to reflect on our common standpoint on particular processes currently taking place: the privatization of interest and commonalization of resources. We further ask what it specifically means for education, art, and culture. The dialogue probes these questions from the perspective of an educator and an engineer, respectively. Nora Sternfeld's practice originated in radical pedagogy, philosophy, and cultural studies, while Grégoire Rousseau, after training as an electrical engineer, has been active in alternative sound art practices since the mid-1990s.

All over the world, education-which is understood differently, as a universal right and public good-is facing processes of economization and privatization. Technology - which is also understood differently, as a common means of production, collaboratively developed-is being taken away from the public and put into corporate hands. Against this background, our conversation proposes a radical understanding of postinternet art education. It explores necessary convergences in radical practices, as well as possible future strategies for education and open technology. The exchange ranges widely across ideas of resistance, emancipation, and commoning practices. Specifically, we ask how new models of understanding technology and education as commons can challenge the neoliberal agenda and move away from established policies, and how a collective re-appropriation of the means of production-in particular in communication and education-could emerge within a post-digital society. 
Working together in a discursive open laboratory, we investigate the possibility of a collective effort to learn from each other and from our respective approaches, theories, knowledges, and know-how. These derive from substantially different experiences and practices. This conversation stages an encounter between our knowledges and contexts, aiming to find direct intersections in their thought. However, it also seeks to learn from two very different approaches toward the commons. The ultimate aim is the production of dialogue and a space to discuss education and the postdigital from a radical position.

\section{Situating Ourselves}

Nora: As we try to bring our perspectives together, let's start by understanding them. We announced that we speak from a "radical" perspective. But what do we mean by that?

I would regard myself as a radical educator. Let me try to say what this means for me: In theoretical terms, I make strong connections to theories of radical democracy and radical pedagogy. The most important representatives of this re-politicization and democratization of democracy are Ernesto Laclau and Chantal Mouffe, whose book Hegemony and Socialist Strategy: Towards a Radical Democratic Politics (1985) was the first to introduce the term "radical democracy" to the political lexicon (Laclau \& Mouffe, 1985). In terms of my radical pedagogy, I have been very much influenced by the Brazilian educator and philosopher Paulo Freire (1970) and by bell hooks (1994), the African-American writer, teacher, and Black intellectual. Both have written and worked on education as a practice of emancipation and change. The idea of such an endeavor is to collaboratively understand the conditions under which we live, in order for us to change them. In this sense radical education is also critical education: it is critical, collaborative, and transformative.

In Vienna, along with my colleagues Renate Höllwart and Elke Smodics, I am part of trafo.K, a collective we founded in 1999. Here is how we describe our practice:

trafo. $K$ is an office based in Vienna, which works on art education and critical knowledge production. Our projects question social phenomena which are perceived as simply given. We intervene in existing relations, more often than not using unexpected strategies. We are interested in revealing the structures of media and institutions, and in creating public awareness of 
alternative (hi)stories and images. In doing so, we want to find out what is produced when different forms of knowledge, artistic strategies and socially relevant themes are brought together. Our projects are based on collective, emancipatory processes, which allow a variety of perspectives to come into contact, opening up new spaces of agency. (https://www.trafo-k.at/en/ about/)

Does that make sense to you? And how would you describe your own position?

Grégoire: I understand this to mean your pedagogical practice is looking to do more than merely interpret the questions posed. It wants a concrete collective transformative process.

Nora: I am actually not sure if this is that much of a contradiction. Isn't interpreting a question often also a way to change it?

Grégoire: What I said just there was not an attempt to essentialize your work, I am just trying to put it into my own simple words. From my standpoint this very concrete transformative process happens to be crucial: we'll get back to that in relation to commoning practices. However, now I would relate my own pedagogical practice directly to your words, 'we question things that are presented as simply given, and we intervene in existing relations.' I was educated as a computer engineer and worked for many years in industry. My early electronic art practice took inspiration from Situationist approaches, for instance the idea of the "détournement" (Debord \& Wolman, 1956) of my professional working equipment into sound devices in my studio. I even brought these on stage once.

Nora: This actually sounds like a good example of deconstructing the difference between interpreting and transforming. Détournement could be a way to 'interpret' material differently in a very practical sense, to change its 'use' through a different understanding, to re-appropriate the material by taking it so seriously that its interpretation flips.

Grégoire: Exactly. And I would even go further, based on my own experience as an educator in technology: What seems most relevant for me in educational technology as a collective learning process, is the understanding, or awareness, that what is simply given may possess more. The precise idea of what is more cannot be defined, nor should it be expected to be as such. This is the meeting point of art, technology and collaborative practices: It may be a dead end, or an experimental art form, or even a spark triggering something else. The more, as a process, produces a new space for production and emancipation. This is what I mean by 
a collective transformative process, and this is where I would situate my practice. An actual radical technology practice must both comprehend its own position within existing conditions, and from that position, it must produce an action of return toward public hands. This may simply sound like another form of analysis, but I can assure you the work is very much hands-on. The on-purpose over-fluidity of media activated by Post Internet Art should only emphasis the hard materiality the Post Digital condition reminds us. Post Digital Commoning practices as demonstrated by Felix Stalder (2013) produce this self-reflective moment to envision together something else. Open Source Technology is one of the early examples of collectively-designed digital production. However, obviously this technological emancipation movement has thus far never happened and will never simply come about by itself.

Nora: And what if we would insist and persist that this emancipation could actually be (and even is) a post-digital or post-internet perspective? Sometimes it seems as if historical discourses and agencies are almost eradicated from actual theories and practices. But this doesn't mean they don't exist.

\section{Converging Histories}

Nora: Here is a point where it seems to make sense to examine the histories of our own approaches and practices. I have worked on the history of radical education and you have written about the history of electricity. In your book, Electric Energy in the Arts, Knowledge Happens Together (Rousseau, 2018) you discuss how technology and electricity could be used for emancipatory practices. Could you give some more insight into that?

Grégoire: That book's point of departure was an investigation into the relation between artistic and scientific practices: What do they share? What makes them different? How one can actually learn from the other in terms of collective knowledge production? Within that context, electrical energy is the red thread running through the entire process. We take electricity for granted in our everyday life, as something we can generate, control and distribute. However, the current situation did not come about by itself nor as the result of a very linear scientific progression. On the contrary, the history of electrical energy was a difficult process of unplanned discoveries, failed attempts, individual and collective efforts, and political struggles. It should not come as a surprise 
that the Italian Futurists considered naming their proto-fascist movement "Elettrissimo" (Blumenkranz-Onimus, 1983). Lenin responded with the slogan, Communism is Soviet Government + Electrification of the Whole Country (Lenin, 1920). At this point, I must make reference to a moment that deeply transformed my practice, both as an electrical engineer and an artist: Quinn Latimer's text and exhibition space "Technology suggests the hands" (Latimer, 2014), which featured in documenta 14. Latimer's work shows how, and why, one of the best-known technology companies exploited Navajo women, taking advantage of the visual similarities between electronic circuit board and traditional Navajo weaving crafts. I realized then that electricity - both as a form of energy, and a technology in digital form-had a particular position within both art practice and education. In this sense, electric energy as form of power and technology produces a space for critical practices and emancipation. However, this must come together with constant, collective reflection on the conditions of its production.

Nora: This brings me directly to what interests me in the history of pedagogy as a critical practice: I would like to bring up two elements we both mentioned earlier: The need to take a stance and the need to take a stance together. Both of these things form part of political education from the very beginning. Peter Mayo (2006), who writes about Antonio Gramsci and Paulo Freire, sums this up in a simple question that probably every political pedagogy must ask: "Which side are we on when we educate and teach, and when we act (Mayo, 2006, p. 20)? The question arises in relation to power: Is education about preserving existing power relations or is it about challenging them? Paulo Freire, the Brazilian pedagogue, liberation theologian and educational theorist, positioned his own approach in this way: "Tactically within the system and strategically outside it" (Mayo, 2006, p. 21). Freire's assumption was that there is no such thing as neutral education. Education is always political, either serving to consolidate existing conditions, or helping to change them.

Radical education's other great question concerns relations within education itself. It questions the undisputed power of the teacher, understanding learning as an active practice of collaboration. In other words, radical education conceives of the essential link between pedagogy and society both in terms of social transformation and of removing the clear distinction between active knowledge production and passive reception. These two goals have been the central aspects of debates on a critical, revolutionary pedagogy, from Marxist approaches in the 1920s through 
the Black Power Movement in the late 1960s, to decolonial approaches today. From here we come to an understanding of education, first as part of the wider struggle and, second, as a collaborative process of learning together, learning from each other.

Another history which interests me is the history of a practice called Kritische Kunstvermittlung in German. Something would go missing if I were simply to translate this term as "critical art mediation," or "critical art education." The German prefix "Ver-" in the original word Vermittlung adds an element of questioning, of crisis, additionally implying something like an "unlearning." Anyway, what I wanted to say is that since the late 1990s this "Kritische Kunstvermittlung"- this art education practice-has developed ways to reflect, question, critique, and reimagine art and the world in various artistic, educational and experimental contexts. To me, this seems very interesting and relevant to our topic. I would describe these practices as reflective, playful, investigative, collaborative, open-ended. They offer solidarity with existing social struggles and are highly critical practices, even though they tend to be formulated from within the art institutions they critique. Janna Graham has described the practices used in this context as Para-Sitic. And I would actually like to ask how these particular approaches can be translated into technology. What would be a technology that is based on critique, on dialogue, and on solidarity? Translating this into strategies for a postinternet art education two words come immediately to mind, forming the possible basis for a convergence: hacking and commons.

\section{What Do We Mean by Commons?}

Nora: In his book Digital Solidarity, Felix Stalder (2013) describes the commons as follows:

The most comprehensive new formations for organizing solidarity are developed through the renewal of the idea and practice of the commons or commoning. These are organized, long term processes by which a group of people manages a physical or informational resource for joint use. (Stalder, 2013 , p. 31)

My own perspective is slightly different. It seems important to me to draw a strong relation between the term commons and the phenomenon of property. I actually understand commons as public property, that which 
belongs to everyone. Let me try to explain this through a museological example: In museology, the history of public collections is often told in connection with the French Revolution. In the Louvre, in fact, something significant happened in relation to the ownership of objects. In the revolutionary museum, the representative objects of the nobility and the Church were made public. This was the result of expropriation, the appropriation of the collections for the general public. If the objects had, until the Revolution, served as representations of the powerful, they were now socialized. In the process, objects underwent a change of meaning, a revolutionary de- and recontextualization. Since then, we have assumed that public museums and their collections are not simply available to everyone, but that they in fact belong to everyone. In the case of the Louvre, the public cannot be understood separately from the fact of property.

Grégoire: Let's remember that revolution first happened, the people collectively re-appropriated that property. In that sense, the property of public objects followed the monopoly of ideology.

Nora: Obviously, we have since lost that tradition. The public itself has increasingly been expropriated: In our own neoliberal era, the public sphere is more and more being separated from property, and thus emptied of its core meaning. What I mean by this is that, in everyday language, we almost naturally assume that private collections, archives, or research centers can be public without giving up their private ownership (think of the Getty Foundation, or of Google Museums). But if modern museum history teaches us that publicness has something to do with common property and not merely with access, then this double status is actually a contradiction in terms. This contradiction has spread particularly rapidly over the last two decades, as the public character of institutions has been increasingly eroded. Public institutions are being quietly privatized, at the same time as we have seen a boom in discourses of "public spaces" and "public programs." And just as with material things, there is no reason why digital objects or digital copies should not belong to everyone.

Grégoire: We have to go further and ask: What if the property at stake is actually in the making, within a dynamic process? What would be a valid strategy when even the precise property cannot be identified? I therefore take a different approach. On this question, I would relate more to the position of architect and educator Stavros Stavrides (2016). Public property, whether a space or object or whatever else, is defined by an authority of some sort which establishes the rules under which people 
may use them. Private property belongs to economic entities which have the right to establish the condition of use. I would say that commons, or commoning practices, integrate something entirely different than the dichotomy between public and private property. They can be defined much more as a relation between a social group and the related collective process. They define a practice that questions and transforms the dominant form of living together.

Nora: This makes sense to me. To grasp the dynamism of the process it might be more appropriate to use the word commoning. But I can also see a problem here. In current debates on urban housing we often hear about "the three sectors: public, private and commons". This sounds like a neoliberal appropriation of the commons. A new way to integrate team work and temporary autonomous zones in the system, which can later be turned into an economic good.

Grégoire: I understand the underlying contradiction: that public property must be re-appropriated in its own full right, not in order to grant access to it as a form of privilege.

\section{Re-Appropriating THE Commons}

Nora: That all sounds very nice, but we seem to agree that right now we are experiencing the economization of all public goods, including the privatization of education and of technology. So, we are further than ever from our ambition. What is to be done to re-appropriate the public, to common education and to educate the commons?

Grégoire: Yes, as you mentioned, transformative processes can be turned into innovations for the market, forms of recuperation by private interest. This is true in the housing sectors, but also in technology. For our project Station of Commons-which I will come back to-we conducted research into one future means of production: open source software. We learned how Open Source became a branding method. It would take quite some time to analyze the ins and outs of the investigation. However, what we can note here is that the digital space has already its own liberated enclaves, ready-made traps. We should not limit the future inside of projected plans put together by someone else. The case of current digitalization practices within museums is one. The digitalization process represents a privatization opportunity. What if we would integrate the Post Digital assessments to think, reflect, and act on the situation? What can we envisage or propose that would be different then? 
Nora: The re-imagination of the world as common can't just be an idea that sounds good, it will either be a re-appropriation or it will not be at all. Because, in fact, the world actually does belong to everyone. Freire teaches us to name this state of affairs and to become aware of our own situation with regard to changing it. We name the world in order to change it. To make it our own again. So, it is about learning that education, culture, museums, knowledge belong to us all, just like housing and water. How do we expropriate the expropriators, the people behind the privatization and economization of culture, museums, education, technology, even the future?

Grégoire: I would suggest that the re-appropriation of the commons, the collectivization of technology, should do more than claim what already exists as our own, since what already exists doesn't work. The term Para-Sitic that you mentioned tends in this direction: it implies a separate body situated in the margins, functioning on its own rules but still forming part of a larger body, a wider structure. Instead of imagining the re-appropriation as static, let's think it as the creation of para-infrastructures. Thinking the Post digital condition requires an understanding on the values of technological development, while acting on Post Internet art demands a grasp on forms and temporalities. Commoning practices are always in the making, gathering a great diversity of knowledge and practices.

Nora: Here we come to a moment of convergence. I would say that radical education is exactly that: The production and sharing of knowledge as a para-infrastructure. And this actually happens all the time, despite processes of neo-liberalization. If we assume that learning can serve to challenge existing hegemonies, this production and sharing happens in two ways: First, existing truths and forms of knowledge often become fragile, debatable, and disputable. Second, other forms of knowledge may come to light. This learning relates to the knowledge of struggles, but also the awareness of other possibilities. In their book The Undercommons, Stefano Harney and Fred Moten speak about the knowledge of the undercommons, something which we can learn from each other (Harney \& Moten, 2013). For this knowledge, Harney and Moten believe that there are always practices of coming together and learning together: in institutions, in the street, at night. This is the context for what they call "study": Spending time together, and with the topics, but without established objectives or schedules. And above all, without credit points (Harney, 2011). This type of learning takes place in the interstices 
of institutions, in the interstices of economization. It is a way in which we learn about another possible world, from each other. And this cannot be done alone, only as a collective process. We could say that while we are doing this, we create frameworks and teach them to each other, frameworks which make it possible to understand the world differently, in very practical terms. We could call it a détournement of understanding, one with a material effect on how the means of production are used.

Grégoire: Let's come back to Open Source processes, both as forms of learning and of production. A piece of software A is developed by a group for a specific purpose. The work is well documented and then shared openly. The commoning dynamic happens when another group faces another requirement and so uses A to develop further its own new piece of software $B$, and so on. There is an open iteration of new production, of both knowledge and know-how. The whole subject requires more investigation in terms of its temporalities, its modes of organization and labor, means of communication, and distribution. This is exactly what I am developing, along with Juan Gomez, in the research project Station of Commons. Station of Commons investigates the possibilities of technology and its re-appropriation as public property. Considering resources as commons integrates the ideas of shared data, open source practices, artifacts, and real time broadcast. A Station of Commons operates as an easily integrable online platform for sharing local resources. The internet infrastructure serves only as practical protocol of communication between stations, not as a centralized server concentrating and accumulating power. This position of autonomy reflects the original concept of the internet: the equality of the client-server relation and the openness of the algorithmic process. Post Digital asks for care, share of resources, technological agencies, and new peer researches. Each Station depends on its own means of digital production, way of thinking, sharing and learning.

Nora: I think we should end this conversation with your practice as a beginning: A new and ongoing process of collaboration. The point of the convergence would take place when we work together to politicize the fields of art education and of technology. For a radical understanding of post-internet art education this would mean educating and finding new approaches and new collective practices. Let's think of them as experiments, as learning processes, as ways of learning from each other, from cyber- and techno-feminism, from radical technology, from the Situationists and the Undercommons. In this way, we can explore, step by step and 
by all means possible, how it is possible to continue, using what exists, to carry out a détournement of existing infrastructure to build Stations of Commons.

\section{REFERENCES}

Blumenkranz-Onimus, N. (1983). The power of the myth. In F. Popper \& M.O. Briot (Eds.), Electra: L'électricité et l'électronique dans l'art au XXe siècle. Musée d'Art Moderne de la Ville de Paris.

Debord, G.-E., \& Wolman, G. (1956). Mode d'emploi du detournement. Les Lèvres nues (8).

Freire, P. (1970). Pedagogy of the oppressed. Continuum.

Harney, S. (2011, July). Stefano Harney on study (interview, part 5). https:// www.youtube.com/watch?v=uJzMi68Cfw0.

Harney, S., \& Moten, F. (2013). The undercommons: Fugitive planning and black study. Minor Compositions.

hooks, b. (1994). Teaching to transgress: Education as the practice of freedom. Routledge.

Laclau, E., \& Mouffe, C. (1985). Hegemony and socialist strategy: Towards a radical democratic politics. Verso Books.

Latimer, Q. (2014). Technology suggests the hand.... In Q. Latimer \& A. Szymczyk (Eds.), The documenta 14 reader. Prestel Verlag.

Lenin, V. (1920, December 22). Report on the work of the Council of People's Commissars. https://www.marxists.org/archive/lenin/works/1920/ 8thcong/ch02.htm.

Mayo, P. (2006). Politische Bildung bei Antonio Gramsci und Paulo Freire: Perspektiven einer verändernden Praxis. Argument Verlag.

Rousseau, G. (2018). Electric energy in the arts: Knowledge happens together. Uniarts/Academy of Fine Arts in Finland.

Stalder, F. (2013). Digital solidarity. Post-Media Lab \& Mute Books.

Stavrides, S. (2016). Common space: The city as commons. Zed Books. 
Open Access This chapter is licensed under the terms of the Creative Commons Attribution 4.0 International License (http://creativecommons.org/licenses/ by $/ 4.0 /$ ), which permits use, sharing, adaptation, distribution and reproduction in any medium or format, as long as you give appropriate credit to the original author(s) and the source, provide a link to the Creative Commons license and indicate if changes were made.

The images or other third party material in this chapter are included in the chapter's Creative Commons license, unless indicated otherwise in a credit line to the material. If material is not included in the chapter's Creative Commons license and your intended use is not permitted by statutory regulation or exceeds the permitted use, you will need to obtain permission directly from the copyright holder.

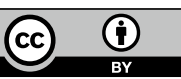

